\title{
Avanços metodológicos na produção in vitro de embriões
}

\author{
Rodolfo Rumpf ${ }^{1}$ \\ 1 - Embrapa Recursos Genéticos e Biotecnologia, CP 02372, 70770-900 - Brasília, DF, Brasil. rodolfo@cenargen.embrapa.br \\ RESUMO - O desenvolvimento da metodologia de produção in vitro de embriões (PIV) para maximizar o ganho \\ genético e a produção animal a um custo baixo é um desafio de pesquisa científica há vários anos. A possibilidade de \\ produzir, em escala comercial, embriões a partir de oócitos puncionados dos folículos ovarianos pode aumentar os \\ benefícios do uso da inseminação artificial devido ao seu decisivo papel no aumento do progresso genético entre \\ gerações de acordo com as necessidades de cada programa de melhoramento genético ou produção animal. Diferentes \\ rotas tecnológicas foram desenvolvidas a partir da PIV em espécies de interesse zootécnico ou espécies ameaçadas de \\ extinção.
}

Palavras-chave: biotecnologia, bovinos, fecundação in vitro

\section{Methodological advances on in vitro embryo production}

\begin{abstract}
The development of in vitro embryo production (IVP) methodology to maximize genetic gain and animal production at lower cost is a challenge of the research and it has been studied for many years. The possibility to produce, in commercial scale, embryos from ovum pick up methodology may increase the benefits of the use of artificial insemination (AI) for its decisive role to maximize the genetic progress between generations, according to the requirements of each genetic improvement program and livestock capacity. Different technological routes are associated to IVP, both for zootechnical interest species and for endangered species.
\end{abstract}

Key Words: biotechnology, bovine, in vitro fertilization

\section{Introdução}

A oferta suficiente de alimentos saudáveis, a prevenção e controle de enfermidades e a sobrevivência harmoniosa do homem nos diferentes ecossistemas é sem dúvida o maior desafio da ciência na atualidade. $O$ investimento na biotecnologia animal no Brasil é respaldado por dois principais fatos. O primeiro é o fato que o Brasil ainda lidera a lista dos países com maior biodiversidade e o segundo, é que o mercado interno por carne e leite é o terceiro maior do mundo. Seguramente, os genes serão a moeda forte do futuro, mas do que adianta possuí-los se não for possível identificálos e torná-los disponíveis para a sociedade?

Os recursos genéticos animais, tanto domésticos como silvestres, comerciais ou em vias de extinção já constituem um dos mais promissores segmentos da economia nacional. Eles represen- tam um nicho capaz de responder rapidamente a investimentos pontuais. Portanto, o que hoje parece distante e utópico do ponto de vista de aplicabilidade pode se tornar uma realidade amanhã, já que o elemento determinante na relação custo/ benefício das modernas biotécnicas de multiplicação animal é o mérito genético do material a ser multiplicado. Neste contexto, fica evidente ainda, a necessidade cada vez maior de interação dos diferentes segmentos da produção animal a fim de atender os aspectos inter e multidisciplinares.

Os marcadores genéticos; a formação de bancos de sêmen, óvulos, embriões e folículos; a sexagem do sêmen; a transferência de embriões; a identificação do sexo do embrião; a produção in vitro de embriões; a clonagem; e a própria transgenia são ferramentas disponíveis aos programas de melhoramento e conservação de recursos genéticos animais. 
É importante salientar, que em se tratando de biotécnica de multiplicação deve-se buscar a melhoria constante dos índices zootécnicos, o monitoramento do desenvolvimento e uso da tecnologia (Carmo et al., 1999; Luna et al., 1999), bem como a identificação de parâmetros cada vez mais eficientes de seleção das doadoras de ovócitos e embriões (Luna.et al., 1997) e dos doadores de sêmen (Bellin et al., 1994; Silva, 1998).

\section{Tecnologia de embriões}

Na transferência de embriões (TE) os esforços se concentram no desenvolvimento de novos protocolos de indução da ovulação múltipla a partir de uma nova geração de hormônios (mais purificados) e informações básicas sobre a foliculogênese (Macmillan, 1999; Fortune \& Rivera, 1999; Caccia, et al., 2000).

A manipulação da dieta das doadoras é também uma alternativa para melhorar as respostas da TE e diminuir os custos (Cavalieri et al., 1999). O objetivo é duplicar as atuais taxas médias de duas a três gestações por colheita e aumentar a frequiência de colheitas para 6 a oito por ano.

A produção in vitro de embriões (PIV) vem apresentando avanços consideráveis e esta sendo lentamente incorporada aos projetos de produção. Com o desenvolvimento do método de punção folicular, tornou-se possível à recuperação de ovócitos de fêmeas vivas para fecundação in vitro (FIV), abrindo novos caminhos para multiplicação de animais de interesse econômico superando os atuais índices da TE clássica, no que diz respeito à produção de bezerro por vaca por ano. Essa técnica pode ser utilizada em animais jovens, gestantes ou lactantes e com problemas de infertilidade adquiridos (Tervit, 1996; Goodhand et al., 1999; Taneja et al., 2000). Sendo que a utilização de bezerras como doadoras de ovócitos em programas de TE oferece um potencial considerável para acelerar o ganho genético pela de redução do intervalo entre gerações (Taneja $e t$ al., 2000). Além disso, possibilita a oferta constante de embriões F1 seja para os programas de produção de leite ou de carne.

A média de ovócitos viáveis obtidos por sessão de punção depende da estratégia adotada.

Assim é possível puncionar os folículos de uma doadora duas vezes por semana, uma vez por semana ou uma vez a cada duas semanas, sendo que, nas duas últimas alternativas é possível melhorar os resultados mediante a estimulação hormonal. Independente da estratégia, o resultado final esperado é de pelo menos uma gestação por semana por doadora (Peixer, et al., 1996; Hasler, 1996; Bols, 1997; Nibart et al., 1997; Rodrigues \& Garcia, 1998; Sauvé, 1998; Goodhand et al., 1999; Bousquet, et al., 2000). Estes resultados estão vinculados às condições clínicas das doadoras, já que boa parte dos animais submetidos a PIV são animais com problemas de fertilidade adquiridos.

Apesar dos avanços obtidos, a produção in vitro de embriões ainda apresenta algumas limitações tais como os baixos índices de blastocisto, dificuldade na criopreservação dos embriões, menor viabilidade dos ovócitos obtidos de bezerras em relação aos de vacas e novilhas, e o custo do embrião que é mais alto do que um embrião de TE. Além disso, bezerros com maior peso ao nascer, período de gestação mais longo, aumento na incidência de abortos, aumento da mortalidade perinatal e aumento de anormalidades congênitas tem sido associados a prenhezes produzidas por transferência de embriões produzidos in vitro (Leibfried-Rutledge, 1999; Wagtendonk de Leew et al., 2000).

O uso comercial em larga escala dessa técnica está, portanto, vinculada a melhoria dos índices zootécnicos e consequentemente a diminuição dos custos. Tendo em vista que a aspiração pode ser feita a campo, enquanto a PIV requer laboratório adequado, a tendência é que ocorra, no Brasil, o mesmo que em outros países como Alemanha, França e Canadá, onde existem laboratórios regionais de PIV que recebem os ovócito aspirados por veterinários que atuam em fazendas. No laboratório é produzido o embrião in vitro que é entregue ao veterinário que o transferirá para vacas receptoras que levarão a gestação a termo.

A PIV trouxe algumas vantagens nos programas de reprodução:

- Com o desenvolvimento de técnicas de reprodução assistida em animais, ocorreu um grande avanço na otimização e multiplicação de fêmeas de interesse não só para a produção animal, mas também para a conservação e regeneração de espécies animais em perigo de extinção.

- A transferência de embriões (TE) propor- 
ciona um melhor aproveitamento de matrizes de elevado mérito genérico, podendo aumentar, em média, 10 vezes o número de crias por ano. Com o advento da produção in vitro de embriões (PIV) esse potencial de multiplicação se torna ainda maior.

- A aspiração de ovócitos imaturos por punções foliculares, associadas à maturação e fecundação in vitro dos mesmos, e ao cultivo in vitro dos embriões, permite que sejam produzidas, em média, 36 crias por ano de uma única fêmea.

- Com o estabelecimento da PIV de embriões, técnicas como a clonagem por transferência nuclear, a injeção intracito-plasmática de espermatozóides (ICSI) e a transgenia podem ser aprimoradas e utilizadas.

- Além de proporcionar, como nova opção, a multiplicação animal, possibilita a utilização de bezerras pré-púberes, vacas em início de gestação, vacas com subfertilidade adquirida e vacas senis.

Impactos:

- Por se tratar de uma técnica relativa nova o monitoramento rigoroso das doadoras de ovócitos, dos ovócitos, dos embriões e das crias nascidas é de fundamental importância para que a mesma possa ser utilizada com segurança, de forma adequada e nas situações mais recomendadas.

- A utilização comercial da PIV ainda está limitada ao seu elevado custo, e vai depender do balanço entre o mérito genético do produto (bezerro) e o custo de sua produção.

- Apesar dos avanços ocorridos nos últimos anos nessa biotécnica, várias questões relacionadas à avaliação da competência biológica dos gametas e ao próprio sistema de cultivo precisam ser esclarecidas. Estudos básicos que estão sendo condu-zidos a nível mundial poderão esclarecer aspectos relativos à maior susceptibilidade dos embriões PIV a criopreservação, a menor viabilidade dos ovócitos de bezerras quando comparados aos de vacas e as baixas taxas de prenhez.

- A PIV está sendo gradualmente integrada a programas de melhoramento genético, como uma ferramenta complementar à inseminação artificial e a transferência de embriões.

- O maior impacto da PIV, todavia, será a sua aplicação associada a sexagem de espermatozóides. Isso porque, com uma dose inseminante sexada será possível produzir em torno de 30 gestações.

Outro método para otimizar a utilização das fêmeas de interesse se refere ao isolamento e cultivo de folículos pré-antrais (FOPA) (Figueiredo et al., 1993). Os FOPAs representam 90\% da população de folículos ovarianos, sendo que a grande maioria degenera e não chega até ovulação. A potencialidade dessa técnica se sustenta nos milhares de ovócitos que podem ser recuperados de um único ovário ou de partes do ovário, podendo ser utilizado como fonte de ovócitos para FIV ou para outras biotécnicas (Lucci et al., 1999). A colheita de tecido ovariano pode ser feita em qualquer idade, estágio do ciclo ou mesmo de animais que morrem subitamente, podendo-se obter grande número de ovócitos de qualquer fêmea (Shaw et al., 2000). Como fonte de ovócitos, os FOPAs devem ser cultivados in vitro até a ovulação, ou o tecido ovariano podem ser transplantado para ovário de doadora da mesma espécie, ou para uma receptora imuno-compatível.

A criopreservação de embriões depende fundamentalmente do estágio de desenvolvimento e qualidade morfológica dos mesmos. A introdução do etilenoglicol como crioprotetor viabilizou a transferência direta, onde a remoção do etilenoglicol ocorre no útero da receptora, sem alterar os resultados até então obtidos com o glicerol (Zanenga \& Pedroso, 1997). A expectativa hoje se volta para a criopreservação dos embriões pela vitrificação com a transferência direta. Os resultados, embora ainda preliminares são promissores e seguramente em breve será possível contar com mais esta tecnologia (Dattena et al., 2000). A criopreservação de ovócitos continua sendo um desafio para a pesquisa, sendo que os melhores resultados também estão relacionados a vitrificação (Vajta, et al., 1998).

A micromanipulação de embriões seja para diagnósticos pré-implantação (por exemplo, a identificação do sexo), seja a própria bipartição visando a produção de gêmeos homozigóticos, depende igualmente do estágio de desenvol-

๑ 2007 Sociedade Brasileira de Zootecnia 
vimento e qualidade morfológica do embrião e do treinamento do técnico. Essas técnicas estão estabelecidas e disponíveis ao setor privado.

A injeção intracitoplasmática de espermatozóide (IICE) é uma técnica amplamente difundida na reprodução assistida humana, mas com resultados ainda baixos em bovinos, embora o primeiro bezerro tenha nascido em 1991(Goto et al., 1991). Atualmente, através da IICE, o uso das células espermiogênicas primordiais e espermatozóides do parênquima testicular e epididimário, podem ser a opção e garantia biológica para a preservação de material de alto valor genético, de reprodutores de idade avançada, e em perigo de extinção. Também a possibilidade de transferência interespecífica de células primordiais e produção da espermatogênese entre espécies como camundongos e ratos (xenogênica) podem se tornar uma realidade nos animais domésticos.

A Transferência Nuclear (TN) para a produção de clones em mamíferos está sendo implantada em alguns laboratórios do Brasil que vem trabalhando com FIV. Embora a fonte clássica de células doadoras de núcleos seja mórulas produzidas in vivo ou in vitro, o estabelecimento de linhagens celulares a partir de células tronco embrionárias e fibroblastos fetais (Garcia et al.,1998; Oliveira, et al.,1999), bem como células espermatogênicas (Feliciano Silva et al., 1998) está sendo perseguido.

A TN está sendo implantada e desenvolvida com os objetivos de modelo científico para diferentes estudos básicos, regeneração de raças/ espécies em vias de extinção, melhoramento animal, e sem dúvida, com o objetivo de dar suporte a produção de animais transgênicos.

A TN - utilizada na clonagem animal - tem diversas aplicações potenciais em diferentes setores estratégicos, sejam científicos ou produtivos. Para o primeiro, podemos citar estudos da interação núcleo-citoplasma da reprogramação nuclear e a questão da herança citoplasmática. Já para o setor produtivo, esta técnica atende a programas de melhoramento genético com a rápida multiplicação de animais com características genéticas desejáveis, proporcionando uma diminuição no intervalo de gerações; ainda podemos apresentar a possibilidade de conservação e regeneração de recursos genéticos em vias de

๑ 2007 Sociedade Brasileira de Zootecnia extinção. Porém, o mais importante impacto desta biotécnica será em combinação com a tecnologia que introduz genes específicos em linhagens celulares a serem utilizadas como fonte de núcleos na transferência nuclear, resultando na produção de clones transgênicos. Estes animais, certamente, terão várias aplicações biomédicas (produção de proteínas de interesses farmacêuticos, alimentos com propriedades nutritivas incrementadas, órgãos para transplante) e características produtivas melhoradas.

A TN não deve ser vista isoladamente, mas sim articulada a outras tecnologias de multiplicação animal, como por exemplo a inseminação artificial, a sexagem de espermatozóides, a transferência de embriões, a fecundação in vitro, dentre outras. O impacto dessas tecnologias fica vinculado à seleção criteriosa do material genético a ser multiplicado, e não é absurdo prever um ganho genético em 1 ano equivalente a 12 anos de seleção e multiplicação por métodos convencionais.As tecnologias relatadas, independente de seu estágio de desenvolvimento, constituem a caixa de ferramentas tecnológicas disponíveis para atender as demandas do setor produtivo. Essas tecnologias são aditivas e não substitutivas, e a estratégias de uso das mesmas está diretamente relacionada ao mérito genético dos doadores.

\section{Literatura citada}

BELLIN, M.E.; HAWKINS, H.E.; AX. R.L. Fertility of range beef bulls grouped according to presence or absence of heparin-binding proteins in sperm membranes and seminal fluid. J. Anim. Sci., v.72, p.2441-2448,1994.

BOLS, P.E.J. Transvaginal ovum pick-up in the cow; technical and biological modifications. Merelbeke: Universidade de Gent, 1997. 228p. (Tese de Doutorado).

BOUSQUET, D.; TWAGIRAMUNGU, H.; DUROCHER, J. et al. Effect of LH injection before ovum pick-up on in vitro embryo production with oocytes collected at differentintervals after the last FSH injection. Theriogenology, v.53, p.347, 2000.

CACCIA, M.; TRÍBULO, R.; TRÍBULO, H. et al. Effect of pretreatment with eCG on superovulatory response in CIDRB-treated beef cattle. Theriogenology, v.53, p.495, 2000.

CARMO,T.F.M.; LUNA, H.S.; LUNA, H. Efeito da superovulação na instabilidade cromossômica de novilhas. Gen. Mol. Bio., v.22, n.3, p.51, 1999 (Supl.).

CAVALIERI, F.L.B. Efeito de flushing nutricional associado ou não ao bst e de dois níveis de concentrado no crescimento folicular, resposta superovulatória e produção de embriões em vacas de corte. Dissertação (Mestrado em Zootecnia) - Escola de Zootecnia da UEM, Maringá. 70p., 2000.

DATTENA, M.; PTAK, G.; LOI, P. et al. Lambing rate following transfer after vitrification of in vitro and in vivo-produced ovine embryos. Theriogenology, v.53,p.252, 2000.

FELICIANO SILVA, A.E.D.; SILVEIRA, L.L.; OLIVEIRA, 
R.R. et al. Isolation and identification of spermatogenic cells as factor potentially used in animal genetic preservation. Arq. Fac. Vet. UFRGS, v.26, n.1, p.259,1998.

FIGUEIREDO, J.R.; HULSHOF, S.C.J.; VAN DEN HURK, R. et al. Development of a new mechanical and enzymatic method for isolation of intact preantral follicles from fetal, calf and adult bovine ovaries. Theriogenology, v.40, p.789799, 1993.

FORTUNE, J.E.; RIVERA, G.M. Persistent dominant follicles in cattle: Basic and appliedaspects. Arq. Fac. Vet. UFRGS, v.7, n.1, p.24-36, 1999 (Supl.).

GARCIA, J.M.; WOLF, A.; SMITH, L.C. Obtenção e caracterização de embryonic stem cells bovina: resultados preliminares. Arq. Fac. Vet. UFRGS, v.26, n.1, p.282, 1998 (Supl).

GOODHAND, K.L.; WATT, R.G.; STAINES, M.E. et al. In vivo oocyte recovery and in vitro embryo production from bovine donors aspirated at different frequencies or following FSH treatment. Theriogenology, v.51, p.951-961, 1999.

GOTO, K.; KINOSHITA, Y.; TAKUMA E. et al. Birth of calves after the transfer of oocytes fertilized by sperm injection. Theriogenology, v.35, p.205, 1991 (Abstr.).

HASLER, J.F. Commercial production of in vitro derived bovine embryos. Arq. Fac.Vet.UFRS, v. 24, n.1, p.117-134, 1996.

LEIBFRIED-RUTLEDGE, M.L. Factors determining competence of in vitro produced cattle embryos. Theriogenology, v.51, p.473-485, 1999.

LOHUIS, M.M. Potential benefits of bovine embryomanipulation technologies to genetic improvement programs. Theriogenology, v.43, p.51-60, 1995.

LUCCI, C.M.; RUMPF, R.; FIGUEIREDO, J.R. et al. Isolation of ovarian preantral follicles from zebu cows: development and efficiency of a specific mechanical. Arq. Fac. Vet. UFRGS, v.27, n.1, p.240, 1999 (Abst.).

LUNA, H.S.; LUNA, H.; RUMPF, R. Estudo da instabilidade cromossômica em bovinos subférteis. Arq. Fac. Vet. UFRGS, v.25, n.11, p.244, 1997 (Supl.).

LUNA, H.S.; RUMPF, R.; LUNA, H. et al. Alterações cromossômicas em ovócitos bovinos maturados in vitro. Arq Fac. Vet. UFRGS, v.27, n.14, p.252, 1999 (Supl.)

MACMILLAN, K.L. Pharmacological control of the oestrous cycle to improve thereproductive performance of cattle. Rev. Bras. Reprod. Anim., v.23, n.2,p.61-64, 1999.

NIBART, M.; MARQUANT, B.; HUMBLOT, P. The application of new reproductive technologies in France. Arq. Fac. Vet. UFRGS, v.25, n.1, p.21-35, 1997.

OLIVEIRA, R.R.; RUMPF, R.; LUNA, H.S. et al. Isolamento, cultivo e criopreservação de fibroblastos fetais bovinos. In: SIMPÓSIO DE RECURSOS GENÉTICOS PARA AMÉRICA LATINA E CARIBE - SIRGEALC, 2., 1999, Brasília. Anais...Brasília:Embrapa Recursos Genéticos e Biotecnologia, 1999. CD-ROM. Editado por Arthur daSilva Mariante e Patrícia Goulart Bustamante.

PEIXER, M.A.S.; RUMPF, R.; BEM, A.R. de et al. Produção de embriões e gestações a partir de ovócitos recuperados por ultrasonografia em fêmeas super-ovuladas. Arq. Fac. Vet. UFRGS, v.24, n.1, p.231, 1996 .

RODRIGUES, C.; GARCIA, J.M. The application of ultrasound guided follicular aspiration in cattle. Arq. Fac. Vet. UFRGS, v. 26, n.1, p.156-159, 1998

SAUVÉ, R. Ultrasound guided follicular aspiration and in vitro fertilization. Arq. Fac. Vet. UFRGS, v.26, n.1, p.141-155, 1998.

SHAW, J.M.; ORANRATNACHAI, A.; TROUSON, A.O. Fundamental cryobiology of mammalian oocytes and ovarian tissue. Theriogenology, v.53, n.1, p.59-72, 2000.

SILVA, A.E.F. Reação acrossômica induzida: Método indicador de fertilidade de touros. In: EMBRAPA RECURSOS GENÉTICOS E BIOTECNOLOGIA, Brasília: Embrapa, 1998. 38p.(Embrapa/Cenargen. Documentos, 35).

TANEJA, M.; BOLS, P.E.J.; VELDE, V. Development competence of juvenile calf oocytes in vitro and in vivo: influence of donor animal, variation and repeated gonadotropin stimulation. Bio. Reprod., v.62, p.206-213, 2000.

VAJTA, G.; HOLM, P.; KUWAYAMA, M. et al. Open pulled straw (OPS) vitrification: a new way to avoid cryo injuries of mammalian ova and embryos. Mol. Reprod. Dev., v.51, p.53-58, 1998 .

WAGTENDONK-DELEEUW, A.M.; MULAART, E.; DE ROOS, J.S. et al. Effects of different reproduction techniques: al, MOET or IVP, on health and welfare of bovineoffspring. Theriogenology, v.53, n.2, p.575-597, 2000.

ZANENGA, C.A.; PEDROSO, M.F. Comparison between the pregnancy rates of frozen bovine embryos with glycerol or ethylene glycol. Arq. Fac. Vet. UFRGS,v.25, n.1, p.145-146, 1997 (Supl.). 